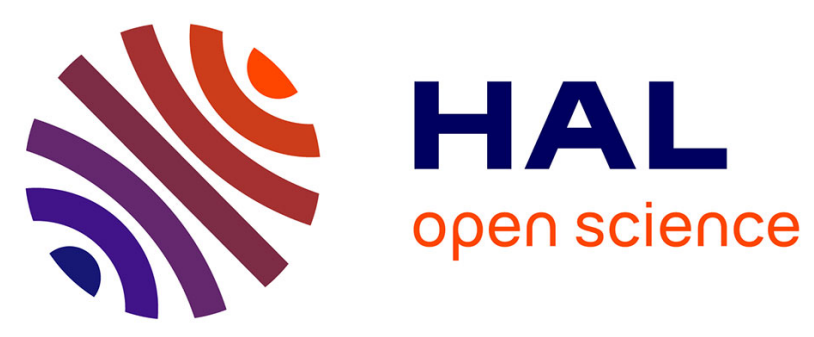

\title{
Older Adults' Reasons for Participating in an eHealth Prevention Trial: A Cross-Country, Mixed-Methods Comparison
}

\author{
Nicola Coley, Anna Rosenberg, Tessa van Middelaar, Alexandra Soulier, \\ Mariagnese Barbera, Juliette Guillemont, Jaap Steensma, Valérie Igier, Marjo \\ Eskelinen, Hilkka Soininen, et al.
}

\section{To cite this version:}

Nicola Coley, Anna Rosenberg, Tessa van Middelaar, Alexandra Soulier, Mariagnese Barbera, et al.. Older Adults' Reasons for Participating in an eHealth Prevention Trial: A Cross-Country, MixedMethods Comparison. Journal of the American Medical Directors Association, 2019, 20, pp.843 849.e5. 10.1016/j.jamda.2018.10.019 . hal-03486382

\section{HAL Id: hal-03486382 https://hal.science/hal-03486382}

Submitted on 20 Dec 2021

HAL is a multi-disciplinary open access archive for the deposit and dissemination of scientific research documents, whether they are published or not. The documents may come from teaching and research institutions in France or abroad, or from public or private research centers.
L'archive ouverte pluridisciplinaire HAL, est destinée au dépôt et à la diffusion de documents scientifiques de niveau recherche, publiés ou non, émanant des établissements d'enseignement et de recherche français ou étrangers, des laboratoires publics ou privés.

\section{(ㅇ)(1) $\$$}

Distributed under a Creative Commons Attribution - NonCommerciall 4.0 International 
Original Study

\title{
Older Adults' Reasons for Participating in an eHealth Prevention Trial: A Cross-Country, Mixed-Methods Comparison
}

\author{
Nicola Coley PhD ${ }^{\mathrm{a}, \mathrm{b}, *}$, Anna Rosenberg MSc ${ }^{\mathrm{c}}$, Tessa van Middelaar MD, PhD ${ }^{\mathrm{d}, \mathrm{e}}$, \\ Alexandra Soulier $\mathrm{PhD}^{\mathrm{a}}$, Mariagnese Barbera $\mathrm{PhD}^{\mathrm{c}}$, Juliette Guillemont $\mathrm{MSc}^{\mathrm{a}}$, \\ Jaap Steensma BSc ${ }^{\mathrm{d}}$, Valérie Igier $\mathrm{PhD}^{\mathrm{f}}$, Marjo Eskelinen $\mathrm{PhD}^{\mathrm{c}}$, \\ Hilkka Soininen MD, $\mathrm{PhD}^{\mathrm{c}, \mathrm{g}}$, Eric Moll van Charante MD, $\mathrm{PhD}^{\mathrm{h}}$,

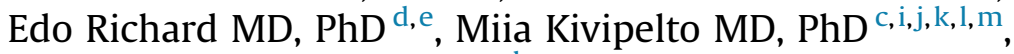 \\ Sandrine Andrieu MD, PhD ${ }^{\mathrm{a}, \mathrm{b}}$, for the MIND-AD and HATICE groups \\ a INSERM-University of Toulouse UMR1027, Toulouse, France \\ ${ }^{\mathrm{b}}$ Department of Epidemiology and Public Health, Toulouse University Hospital, Toulouse, France \\ ${ }^{\mathrm{c}}$ Department of Neurology, Institute of Clinical Medicine, University of Eastern Finland, Kuopio, Finland \\ d Department of Neurology, Donders Institute for Brain, Cognition and Behavior, Radboud University Medical Center, Nijmegen, The Netherlands \\ ${ }^{\mathrm{e}}$ Department of Neurology, Academic Medical Center, University of Amsterdam, Amsterdam, The Netherlands \\ ${ }^{\mathrm{f}}$ EA 17411- CERPPS, Université Toulouse Jean Jaurès, Toulouse, France \\ ${ }^{g}$ Neurocenter, Neurology, Kuopio University Hospital, Kuopio, Finland \\ ${ }^{\mathrm{h}}$ Department of General Practice, Academic Medical Center, University of Amsterdam, Amsterdam, The Netherlands \\ ${ }^{i}$ Division of Clinical Geriatrics, Center for Alzheimer Research, Department of Neurobiology, Care Sciences and Society (NVS), Karolinska Institutet \\ Stockholm, Sweden \\ ${ }^{\mathrm{j} S t o c k h o l m s ~ S j u k h e m, ~ R E D ~ U n i t, ~ S t o c k h o l m, ~ S w e d e n ~}$ \\ ${ }^{\mathrm{k}}$ Neuroepidemiology and Ageing Research Unit, School of Public Health, Imperial College London, London, United Kingdom \\ ${ }^{1}$ Institute of Public Health and Clinical Nutrition, University of Eastern Finland, Kuopio, Finland \\ ${ }^{\mathrm{m}}$ Theme Aging, Karolinska University Hospital, Stockholm, Sweden
}

\section{Keywords:}

Patient recruitment

randomized controlled trial

motivation

telemedicine

autonomy

\begin{abstract}
A B S T R A C T
Objectives: To explore older adults' reasons for participating in a multinational eHealth prevention trial, and compare motivations between countries.

Design: Cross-sectional mixed methods research using quantitative and qualitative approaches (the ACCEPT-HATICE study).

Setting and Participants: Substudy conducted during the recruitment phase of an 18-month RCT testing the efficacy of an eHealth intervention for self-management of risk factors for cardiovascular disease (CVD) and cognitive decline in older adults in Finland, France, and the Netherlands. Participants were 343
\end{abstract}

N. Coley, A. Rosenberg, and T. van Middelaar contributed equally to the study. The authors declare no conflicts of interest.

Funding sources: This work was conducted as part of the MIND-AD and HATICE projects.

MIND-AD is an EU Joint Programme - Neurodegenerative Disease Research (JPND) project, which is supported through the following funding organizations under the aegis of JPND (www.jpnd.eu): Finland, Academy of Finland (291803) and VTR, Kuopio University Hospital (5772815); France, Agence National de la Recherche [French National Agency for Research (ANR), ANR-14-JPPS-0001-02]; Germany, Bundesministerium für Bildung and Forschung (The German Federal Ministry of Education and Research [BMBF], FKZ01ED1509); Netherlands, ZonMw (The Netherlands Organization for Health Research and Development, 733051041); and Sweden, Swedish Research Council (529-2014-7503), the Stockholm Sjukhem foundation.

HATICE was supported by the European Union's Seventh Framework Programme (FP7/2007-2013; grant agreement number 305374). The funders played no role in the study design, collection, analysis, or interpretation of data nor in the writing of this report or the decision to submit the article for publication.

Study group members: The members of the MIND-AD group are Miia Kivipelto, Shireen Sindi, Alina Solomon (Karolinska Institutet, Stockholm, Sweden); Sandrine
Andrieu, Nicola Coley (INSERM-Toulouse University UMR1027, Toulouse, France); Hilkka Soininen, Anna Rosenberg (University of Eastern Finland, Kuopio, Finland); Edo Richard, Tessa van Middelaar (Academic Medical Center, University of Amsterdam, Amsterdam, The Netherlands); Tobias Hartmann (Saarland University, Germany); Carol Brayne (University of Cambridge, Cambridge, UK). The members of the HATICE group are Edo Richard, Pim van Gool, Eric Moll van Charante, Cathrien Beishuizen, Susan Jongstra, Tessa van Middelaar, Lennard van Wanrooij, Marieke Hoevenaar-Blom (Academic Medical Center, University of Amsterdam, Amsterdam, The Netherlands); Hilkka Soininen, Tiia Ngandu, Mariagnese Barbera (University of Eastern Finland, Kuopio, Finland); Miia Kivipelto, Francesca Mangiasche (Karolinska Institutet, Stockholm, Sweden); Sandrine Andrieu, Nicola Coley, Juliette Guillemont (INSERM-Toulouse University UMR1027, Toulouse, France); Yannick Meiller (Novapten, Paris, France); Bram van de Groep (Vital Health Software, Ede, the Netherlands); Carol Brayne (University of Cambridge, Cambridge, UK).

* Address correspondence to Nicola Coley, PhD, INSERM-Université de Toulouse UMR1027, Faculté de Médecine, 37 allées Jules Guesde, 31000 Toulouse, France.

E-mail address: nicola.coley@inserm.fr (N. Coley). 
dementia-free community dwellers aged $65+$ with basic computer literacy and either $\geq 2$ cardiovascular risk factors or a history of CVD/diabetes.

Measures: Online questionnaire (quantitative data) and semistructured interviews (qualitative data). Results: Contributing to scientific progress, wanting to improve one's lifestyle, and benefiting from additional medical monitoring were the predominant reasons for participating. Altruistic reasons were particularly relevant among the French, whereas Finnish and Dutch participants mainly emphasized the benefits of lifestyle changes and regular medical checkups. During interviews, preventing functional dependency emerged as a key underlying motivation. Although some trial design features influenced the decision to participate, the use of an eHealth intervention was not an important motivator in this population. Conclusions/Implications: Altruism and personal benefits motivated older adults to participate in the trial; emphasizing such aspects could facilitate recruitment in future RCTs. Additional medical monitoring may be particularly appealing when access to public health care is considered limited. Furthermore, maintaining autonomy and preventing functional dependency emerged as a key concern in this population of young older adults.

(c) 2018 AMDA - The Society for Post-Acute and Long-Term Care Medicine.

Given the unprecedented aging of the global population, ${ }^{1}$ there is an urgent need for strategies to encourage healthy ageing and prevent age-related disorders, such as cardiovascular disease (CVD) and dementia. Healthy lifestyle and successful management of cardiovascular risk factors are thought to play an important role in this regard, ${ }^{2}$ but conclusive evidence and guidelines about effective and comprehensive interventions, particularly for dementia, are lacking. Selfmanagement might improve guideline adherence, and, with rising Internet use in older age groups, ${ }^{3}$ eHealth interventions targeting CVD and dementia risk factors, and promoting a healthy lifestyle, could be an innovative tool to encourage this. ${ }^{4}$

Randomized controlled trials (RCTs), which are needed to demonstrate the efficacy of interventions, are challenging in older populations, not least because of difficulties with recruitment, which can threaten their validity. ${ }^{5-7}$ Therefore, RCTs targeting this age group are relatively uncommon, ${ }^{8}$ particularly those testing eHealth interventions. ${ }^{9}$

A better understanding of older adults' motivations for participating in RCTs could improve the design and recruitment of future trials, thus increasing the validity of findings, and also facilitate the implementation of interventions at the population level. However, little is known about older adults' opinions on and reasons for participating in $\mathrm{RCTs}^{6}{ }^{6}$ particularly in the context of lifestyle-based prevention or eHealth trials. Furthermore, it is unclear whether motivations differ between countries, because previous studies have generally related to trials conducted in a single country. ${ }^{8}$ Culture- and context-specific differences may occur, because perceptions of healthy and successful ageing vary across different countries and cultures, ${ }^{10}$ and attitudes toward ageing influence health behavior and engagement in prevention. ${ }^{11}$

The primary aim of this analysis was, therefore, to explore older adults' reasons for participating in a European multinational eHealth prevention trial, and to compare motivations between countries. Furthermore, we aimed to specifically assess the influence of using an Internet intervention on the decision to participate.

\section{Methods}

\section{Setting and Participants}

ACCEPT-HATICE was a mixed-methods substudy of the "Healthy Ageing Through Internet Counselling in the Elderly" (HATICE) trial (ISRCTN48151589). Quantitative and qualitative approaches were used in order to explore reasons for participation among our entire sample, and gain a comprehensive understanding of underlying motivations in a subsample. HATICE was an 18-month RCT testing the efficacy of an interactive Internet platform to improve the self-management of CVD risk factors for the prevention of CVD and cognitive decline. ${ }^{4,12,13}$ Between
March 2015 and August 2016, a total of 2724 dementia-free community dwellers aged 65+ with (at least) basic computer literacy and either 2 or more CVD risk factors or history of CVD or diabetes were enrolled in Finland, France, and the Netherlands. Eligibility was verified during a screening visit, and a baseline visit was conducted within 2 weeks. Potential participants were identified and recruited primarily through (1) a population registry (Finland); (2) commercial mailing lists and a prevention center (France); and (3) general practitioners (GPs) (Netherlands) (Supplementary Material, Table A1). Participants were randomized to either an interactive Internet platform, designed to encourage goal setting and lifestyle changes with the remote support of a lifestyle coach, or a control platform with basic health information but no interactive features or coach support. Owing to the nature of the intervention, complete double blinding was not possible, but masking was attempted by informing participants only that they would be randomized to one of 2 Internet platforms (without further details on their content).

From April 2016 onward (because of funding and logistical constraints, the ACCEPT-HATICE substudy began after the start of the HATICE recruitment period), individuals scheduled for a HATICE screening visit (a priori eligible for the trial) were invited to complete the ACCEPT-HATICE questionnaire, preferably prior to screening, or otherwise between the screening and baseline visits (Table A1, Figure 1). Individuals who were ultimately not included in the HATICE trial, either because of ineligibility or withdrawal, were excluded from this analysis. A convenience sample of respondents (selected essentially on the basis of logistical constraints), who agreed to be recontacted, were invited for semistructured interviews within 3 months of their baseline visit. It was planned, given anticipated data saturation (because of the expected homogeneity of study populations within each country), to perform approximately 15 interviews per country, and to maintain a balance between male/female and control/intervention participants.

HATICE and ACCEPT-HATICE were approved by local ethics committees in each country, and all participants provided written informed consent.

\section{Data Collection}

An online questionnaire exploring reasons for participating in the HATICE trial (Appendix) was adapted from a questionnaire designed for a previous study. ${ }^{14}$ Respondents were asked to what extent they agreed with a predefined list of statements relating to reasons for participating in the trial, and whether or not each statement was a reason why they agreed to participate. They could also specify other reasons, and were then asked which was their main reason for participating.

Semistructured interviews were conducted using a standard topic list (Appendix) harmonized across the 3 countries, and covering an 


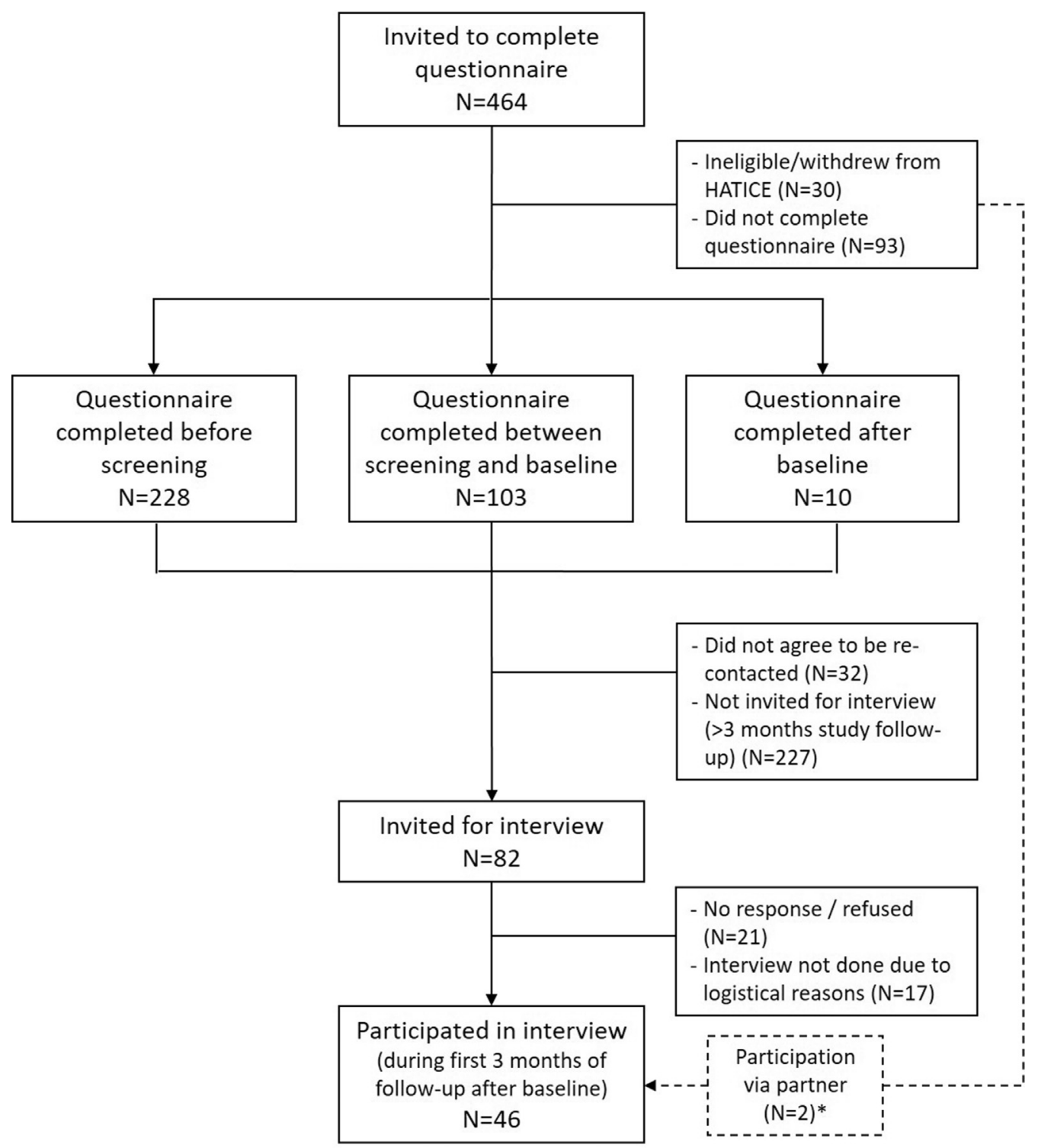

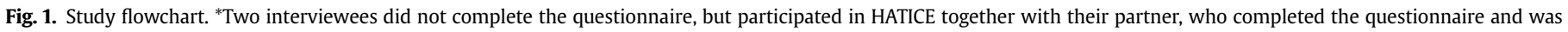
invited for an interview.

initial introduction of the interviewee, general perspectives on health and prevention, and reasons for participation. The topic list and recommended procedures for conducting the interviews were based on the researchers' previous experience ${ }^{14}$ and the literature. ${ }^{15,16}$ Interviewers were not aware of questionnaire responses. All interviews were recorded and transcribed ad verbatim in their original language.

\section{Data Analysis}

Questionnaire respondents' characteristics and reasons for participating were compared between countries using analysis of variance or Kruskal-Wallis tests for continuous variables, and chisquared or Fisher exact tests for categorical variables. Analyses were performed with Stata version 14.1 (StataCorp LP, College Station, TX).

Structured content analysis was applied to interview data. ${ }^{17}$ In each country, 2 independent researchers coded all interviews in the local language, using NVivo (version 11) or ATLAS.ti [version 1.6.0 (484)] software. The coding framework, initially based on the topic list, evolved inductively during regular meetings, held to ensure intercoder consistency within and across countries, until it captured the core themes. After local researchers reached consensus, core themes and quotes were translated into English. The formal content analysis was complemented by interpretive and iterative analyses designed to reveal the key trends in each country and identify between-country differences. Quantitative and qualitative results were interpreted in parallel, and main themes were aligned.

\section{Results}

A total of 341 participants completed the questionnaire (191 in Finland, 103 in France, 47 in the Netherlands), and the overall response rate was $79 \%$ (Finland: $81 \%$, France: $72 \%$, Netherlands: $87 \%, P=.039$ ). Two-thirds of the questionnaires were completed before the screening visit (Figure 1). The median age of the respondents was 68.7 years, $48 \%$ were male, and $51 \%$ had university-level education. Finnish respondents were younger than French and Dutch respondents and had slightly poorer cognitive and physical performance but were more physically active (Table 1 ). 
Table 1

Characteristics of Questionnaire Respondents, by Country

\begin{tabular}{|c|c|c|c|c|}
\hline & Finland $(n=191)$ & France $(n=103)$ & Netherlands $(n=47)$ & $P$ \\
\hline Recruitment method & & & & $\mathrm{N} / \mathrm{A}$ \\
\hline Invitation letter (pop. registry) & $191(100.0 \%)$ & - & - & \\
\hline Invitation letter (GP patients) & - & - & 47 (100.0\%) & \\
\hline Invitation letter (mailing list) & - & $10(9.7 \%)$ & - & \\
\hline Prevention center & - & $79(76.7 \%)$ & - & \\
\hline Other* & - & $14(13.6 \%)$ & - & \\
\hline \multicolumn{5}{|l|}{ Socio-demographic characteristics } \\
\hline Age & $67.8[66.5-69.8]$ & $70.5[67.3-74.0]$ & 69.6 [66.9-74.9] & $<.001$ \\
\hline Male & $84(44.0 \%)$ & $58(56.3 \%)$ & $21(44.7 \%)$ & .117 \\
\hline University education & $99(51.8 \%)$ & $56(54.4 \%)$ & $18(38.3 \%)$ & .170 \\
\hline Married/living with partner & $155(81.2 \%)$ & $75(72.8 \%)$ & $32(68.1 \%)$ & .084 \\
\hline \multicolumn{5}{|l|}{ Cognition, mood and physical performance } \\
\hline MMSE & 28 [27-29] & 29 [28-29] & $29[28-30]$ & $<.001$ \\
\hline GDS & $1[0-3]$ & $1[1-4]$ & $1[1-2]$ & .300 \\
\hline SPPB & 11 [10-12] & $12[11-12]$ & $12[11-12]$ & $<.001$ \\
\hline \multicolumn{5}{|l|}{ Cardiovascular risk profile } \\
\hline Current smoker & $14(7.7 \%)$ & $5(5.1 \%)$ & $1(2.3 \%)$ & .389 \\
\hline Obesity (BMI $\geq 30)$ & 75 (39.3\%) & $27(26.2 \%)$ & $18(38.3 \%)$ & .073 \\
\hline Hypertension & $149(78.0 \%)$ & $75(72.8 \%)$ & $36(76.6 \%)$ & .606 \\
\hline Dyslipidemia & $182(95.3 \%)$ & $100(97.1 \%)$ & $47(100.0 \%)$ & .318 \\
\hline Diabetes mellitus & $39(20.4 \%)$ & $13(12.8 \%)$ & $9(19.2 \%)$ & .257 \\
\hline$<150$ minutes of moderate intensity physical activity/week & $30(15.7 \%)$ & $35(34.0 \%)$ & $11(23.4 \%)$ & .002 \\
\hline History of CVD & $35(18.5 \%)$ & $21(20.8 \%)$ & $10(21.3 \%)$ & .854 \\
\hline
\end{tabular}

Note. Bold values are statistically significant $(P<.05)$.

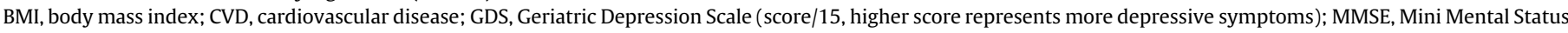

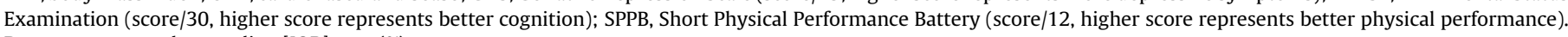
Data are presented as median [IQR] or $\mathrm{n}(\%)$.

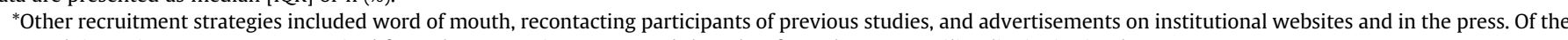
13 French interviewees, 12 were recruited from the prevention center and the other from the mass mailing list invitation letter.

${ }^{\dagger}$ At least 1 of the following: stroke/transient ischemic attack, myocardial infarction, angina pectoris, and/or peripheral arterial disease.

Fifteen, 13, and 18 participants were interviewed in Finland, France, and the Netherlands, respectively, on average 1.7 (range: $0.2-$ 3.2) months after their HATICE baseline visit (Figure 1).

Compared to the other HATICE participants who did not participate in ACCEPT-HATICE, those who participated in this substudy were younger, had a higher level of education, a lower Mini Mental State Examination score, and a better cardiovascular risk profile (Supplementary Material, Table A2). Furthermore, Finnish and French participants were over-represented in the ACCEPT-HATICE sample compared with the entire HATICE population, and Dutch participants were under-represented.

\section{Most Common Reasons for Participating in the HATICE Trial}

Figure 2 shows reasons for participation, based on questionnaire results. Being interested in contributing to scientific progress (85\% of all respondents), believing that improving diet and/or increasing level of physical exercise can have personal health benefits ( $84 \%)$, and the fact that participating would bring about additional medical monitoring (79\%) were the 3 most common statements respondents agreed were reasons for participating in the trial. However, there were some between-country differences. Notably, significantly more respondents in France (96\%) and the Netherlands (94\%) agreed that contributing to scientific progress was a reason for participation, compared to Finland (77\%; $P<.001)$, and Finnish (91\%) and French (82\%) respondents were more likely to agree that the potential health benefits of improving diet and/or increasing level of physical exercise were a reason for participating than Dutch respondents $(62 \% ; P<.001)$ (Figure $2 \mathrm{~A}$ ).

Respondents also most frequently gave one of these 3 reasons as their main reason for participating, but although each one was cited by approximately a quarter of Finnish respondents, the most frequent main reason in France (51\%) and the Netherlands (37\%) was "being interested in contributing to scientific progress" (Figure 2B). Additional medical monitoring was cited as the main reason by $11 \%$ and $13 \%$ of French and Dutch respondents, respectively.
These were also the most common reasons for participation evoked by interviewees. In-depth analysis of interview data is presented below to provide further insight into these reasons and crosscountry differences.

\section{Contributing to science and altruism}

Contribution to science and altruistic reasons were frequently mentioned by interviewees in all countries as reasons to participate. Dutch and Finnish interviewees tended to talk about the usefulness of medical research in general terms, and altruistic motives were discussed broadly and/or in addition to other more important reasons, including personal benefits (Supplementary Material, Table A3, quote 1). In Finland, many participants had previously taken part in studies and considered it a "duty" to participate in medical research (Table A3, quote 2). French interviewees, however, gave specific meaning to their participation in a trial targeted toward healthy ageing, expecting it to contribute to a better understanding of healthy ageing and, thus, to improve the quality of life of the oldest old-a group to which they will soon belong to themselves. Ageing and being dependent on others evoked anxiety and fear, and many interviewees reported negative experiences concerning the care of older adults in institutions (Table A3, quote 3). Such interviewees were particularly prone to cite "contribution to science" as their main reason for participation in HATICE and to admit that they would not necessarily commit to other kinds of studies (Table A3, quotes 4 and 5).

\section{Improving lifestyle}

Lifestyle improvement was also frequently mentioned as a reason for participation during interviews and was expanded on particularly by Dutch and Finnish interviewees. Some had a specific goal in mind, such as weight reduction, increasing physical activity, or improving dietary habits, or had already embarked on adopting a healthier lifestyle, and hoped that HATICE could provide external motivation and 

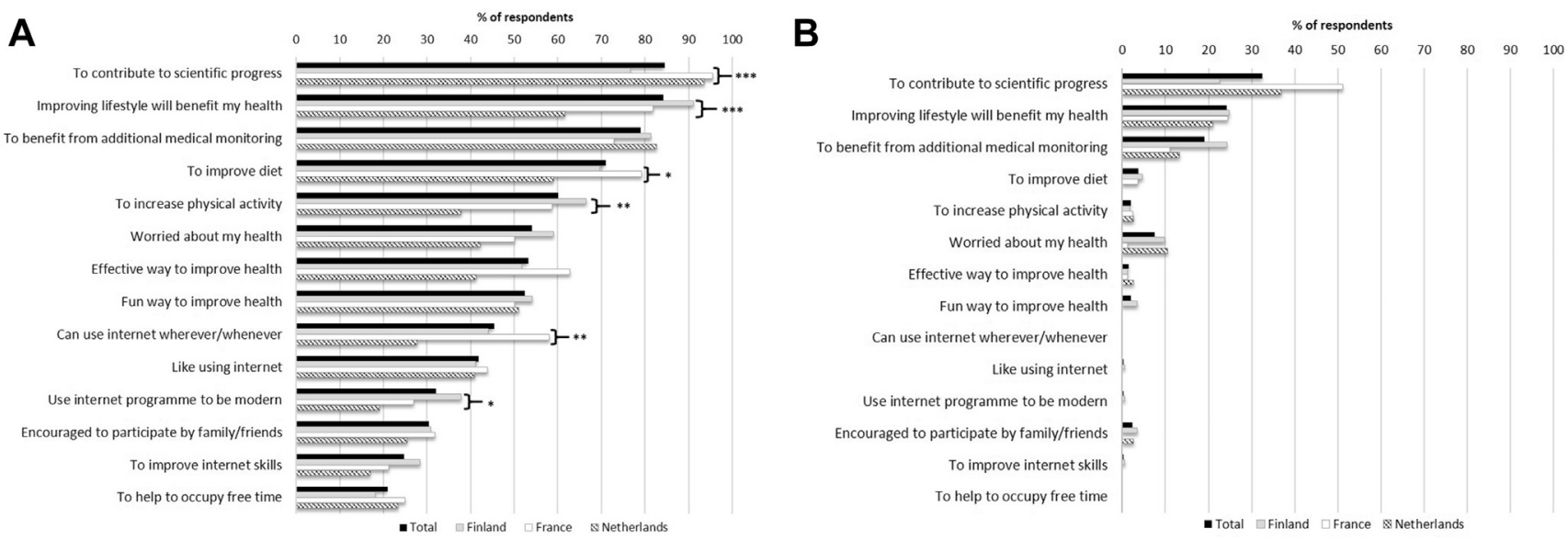

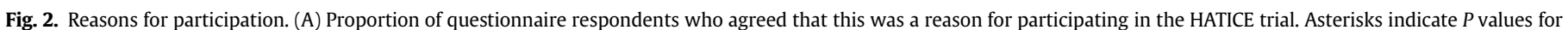

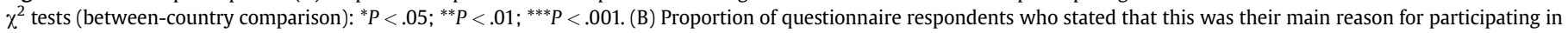
the HATICE trial.

support (Table A3, quote 6). Lifestyle changes were generally perceived as useful for the prevention of CVD in all 3 countries; however, the purpose of and motivation toward improved lifestyle did not seem to be preventing CVD as such, but to improve both current and future health and quality of life (Table A3, quote 7). Again, preventing functional dependence was a common concern (Table A3, quotes 8 and 9). Furthermore, some Dutch and Finnish interviewees hoped that lifestyle improvement would allow them to reduce or avoid medication (Table A3, quotes 10 and 11), and some Dutch interviewees felt it was an obligation to themselves and/or their physicians to pursue a healthier lifestyle (Table A3, quote 12).

\section{Medical monitoring}

Additional medical monitoring was an important reason for participating for Finnish and Dutch interviewees (Table A3, quote 13). It attracted not only proactive individuals already monitoring their health but also those who were less worried about their health or tended to postpone or avoid seeking medical advice. For such individuals, participation provided a free and convenient opportunity to ascertain their health status (Table A3, quote 14). In the Netherlands, interviewees who appreciated medical monitoring often mentioned that they did not expect anything to be wrong; they merely felt comforted by the checkup. In Finland, interviewees considered medical monitoring in HATICE relevant because of difficulties accessing regular health care, particularly for prevention purposes, and notably after retirement when occupational health care services are no longer available (Table A3, quote 15). For some Finnish and Dutch interviewees, detection of $\mathrm{CVD} /$ memory disorders or their risk factors also motivated participation, particularly when there was a family history of such conditions (Table A3, quote 16). French interviewees did not spontaneously mention medical monitoring as a motive for participation, but frequently mentioned having a trustworthy relationship with their GP, and that regular health care was easy to access.

\section{Impact of Internet, and Other Reasons for Participating in the HATICE Trial}

Overall, less than $5 \%$ of questionnaire respondents stated that an Internet-related factor was their main reason for participating (Figure 2B). The majority, however, agreed that using an Internet platform was a fun and/or effective way to improve health (Figure 2A). Other Internet-related factors influenced participation for less than
$50 \%$ of respondents, and some between-country differences were observed (Figure 2A). Interviewees did not consider Internet-related factors a major influence on their decision to participate. However, contributing to the development of an Internet health tool, and the convenience of having continuous access to an Internet intervention were mentioned by some (Table A3, quote 17). Interviewees with more computer experience, in particular, thought that Internet could be a useful tool to improve lifestyle, and while Internet in general was sometimes considered an unreliable source of information, the HATICE platform was considered trustworthy as it was offered by the university (Table A3, quote 18). Potential barriers to participation associated with Internet use included lack of confidence in computer skills, although basic level of computer literacy was a prerequisite for HATICE participation (Table A3, quote 19). Also, the importance of social interaction and communication, even in an Internet-based intervention trial, was emphasized.

Several other reasons for participation emerged from the questionnaires and interviews, including being influenced by the invitation letter. A personalized letter, particularly for Dutch participants, when signed by their GP, conveyed a sense of reliability and trustworthiness (Table A3, quote 20). Participants felt chosen and honored to be asked to participate, and some experienced the letter as a recommendation by health care professionals. Distance to the study center and small number of visits (Table A3, quote 21), occupying free time, getting a distraction during a stressful life period, and getting new information about CVD and memory disorders were also mentioned. Furthermore, participation was considered as fun, an opportunity to interact with people, and a way to satisfy curiosity. The nonpharmacologic nature of the intervention attracted some participants.

\section{Discussion}

In this cross-national, mixed-methods study involving older European adults, altruistic reasons, wanting to improve one's lifestyle, and benefiting from additional medical monitoring were the most frequent reasons for participating in an eHealth prevention trial. There were, however, some between-country variations in the level of importance given to each reason. Maintaining autonomy and preventing functional dependency, both for the participants themselves and for others, emerged as a key concern. The use of an Internet intervention did not seem to be a major motivator for participating in this trial. 
Table 2

Recommendations for Designing Recruitment Strategies and Interventions for Future Trials Promoting Healthy Ageing in Older Adults

Recruitment

When inviting older adults to participate in future trials, recruitment could be facilitated by emphasizing:

- Potential personal benefits, such as regular medical checkups and contacts with health care professionals, particularly when access to them is difficult in the local public health care system. For some older adults, this can facilitate the early detection of health problems, whereas for others it can provide reassurance that they are in good health. However, it should be underlined that participation in a trial does not and should not replace regular health care.

- Potential societal benefits, particularly those affecting older adults, such as preventing loss of autonomy.

- Influential study design features, including the involvement of respected local institutions or people (eg, hospitals, universities, or GPs); the logistical constraints (or lack thereof) of taking part (eg, the number and location of study visits); and the expected ease of use of any technological devices required for the trial (which older adults may not be familiar or confident with, or mentioning that training will be provided to use such devices).

Intervention design

The following findings could be incorporated into the design of future interventions:

- Health information available on the Internet can be perceived as unreliable by older adults, and so receiving understandable and accurate information from a reliable source, particularly regarding cardiovascular diseases and memory disorders/dementia, would be a benefit.

- Older people seem to require specific practical advice and encouragement about making lifestyle changes, particularly concerning diet and exercise, even if they are already motivated to do so.

- Having real-life (ie, in person or by telephone) social interaction and communication are important elements to consider when designing interventions for older adults.

- Older adults may not feel confident about participating in an Internet-based intervention, even if they have basic computer skills. Sufficient emphasis should therefore be given to training and ease of use for such interventions.

As in previous studies, ${ }^{6,8}$ wanting to support research and help others were frequent reasons for participating in the HATICE trial. However, contrary to Dutch and Finnish interviews, French interviews suggested that rather than pure altruism (a concern for others in general), participation in this trial could be considered a fruit of social identification (a concern for a specific group, in this case older adults). ${ }^{18}$ Traditional kinship relationships, attitudes, and policies regarding the care of older adults vary across Europe, ranging from the Nordic public service model to the Southern European family care model, ${ }^{19-22}$ which may explain our findings. Furthermore, the French participants were recruited in southwest France, where the family care model is currently shifting toward public service, ${ }^{23,24}$ which may evoke fear about the changing and unfamiliar care patterns for this age group, particularly given the negative experiences reported of old-age dependence and its management, especially in nursing homes.

Particularly in Finland and the Netherlands, improving one's lifestyle was an important reason for participating, consistent with views of younger intervention trial participants, ${ }^{25}$ but again, as in France, interviews revealed that the underlying motivation of lifestyle improvements in this age group was to maintain functional independence. Interviewees in all 3 countries emphasized the importance of staying active and independent and seemed to share a similar perception of healthy ageing. Indeed, previous research investigating key determinants of healthy and successful ageing has shown that independence, vitality, and ability to function are important issues for older adults, especially in Western countries. ${ }^{26-28}$

Consistent with previous studies, ${ }^{29-31}$ our findings also indicated that personal health benefits and additional medical attention motivate older adults to participate in a lifestyle-based prevention trial; however, the emphasis given to medical monitoring varied between countries, as it was an important factor both in Finland and in the Netherlands but not in France, perhaps because of differences in perceived access to health care. Finnish older adults, in particular, seemed to be motivated to participate for this reason, potentially because satisfaction with health care and perceived access to services has decreased in Finland over time, ${ }^{32,33}$ and having unmet medical needs is more common than in other countries, including France and the Netherlands. ${ }^{34}$ Although access to health care is not necessarily easier in France, ${ }^{35}$ people perceive the quality of their care as relatively higher than in other European countries. ${ }^{32}$ Furthermore, most French participants felt they already received sufficient care, and that HATICE was complementary to existing health services.

The involvement of physicians in the recruitment procedure appeared to influence the decision to participate in the HATICE trial, either because participants thought that their GP had endorsed the trial or because they felt they owed it to their GP to try to make lifestyle changes. The concept of medical authority is known to have an impact on medical practices, such as diagnosis, ${ }^{36}$ and, based on the findings of a previous study, it could also influence older patients', for example those with cancer, decision to participate in clinical trials. ${ }^{37}$ Our study adds to this finding, and suggests that medical authority may also influence the decision to participate in prevention trials targeting healthy older adults.

The main limitations of our study relate to selection bias. First, we used different recruitment methods in each country (eg, many French participants were recruited through a prevention center, whereas in the Netherlands, letters were sent to all potentially eligible patients in GP practices), which probably affected the between-country comparability of our samples. However, the different settings add diversity to our findings, and all participants nonetheless met the same eligibility criteria for the HATICE trial. Second, our participants are not representative of the entire older populations in the respective countries. Prevention trial participants tend to be healthier and more highly educated than the general population, ${ }^{38}$ and indeed, $51 \%$ of ACCEPTHATICE participants had university-level education, compared to $12 \%$, $14 \%$, and $18 \%$ of the general population aged 65 and older in Finland, France, and the Netherlands, respectively. ${ }^{39-41}$ This selection bias could have been further increased in our study because in order to be eligible, individuals had to have basic computer skills, which may also have influenced their views about participating in an Internet intervention. Finally, our sample was relatively small, and we only approached a convenience sample of HATICE participants, not all of whom agreed to participate in this substudy. Despite high response rates, this subsample showed significant differences in baseline characteristics compared with other HATICE participants, not all of which may be explained by differential representation of the 3 countries.

Given these selection biases, it is vital to also study reasons for nonparticipation in lifestyle and eHealth prevention trials among older people, particularly those with lower levels of education and poorer health, who are less likely to participate in such trials but who might derive the most benefit from a successful intervention. Such studies would help to better understand the barriers preventing this population from engaging in preventive actions and could inform the design of strategies to overcome these barriers. It would also be helpful to explore whether disabilities, notably related to vision and hearing, influence older adults' decision to participate in prevention trials, and to offer interventions that can be adapted for individuals affected by such disabilities. 
Nonetheless, to our knowledge, this is the first study examining older adults' reasons for participating in an eHealth prevention trial. Our work is strengthened by our cross-national approach, which highlighted the influence of differences in health, culture, and social care systems. This approach was itself complemented by the use of mixed methods, which enabled us to enhance our interpretation of the quantitative results by more deeply exploring context-dependent issues during qualitative interviews. Additionally, our study was conducted during the recruitment phase of a real-life trial, rather than asking opinions about participating in a hypothetical trial, as in some previous studies. ${ }^{42}$

In addition to informing the design of recruitment strategies in future trials promoting healthy ageing, our results could help to better tailor future intervention strategies to the needs and desires of older adults, which in turn could improve recruitment. Table 2 presents our recommendations based on our findings, some of which reinforce previous results relating to the HATICE trial. ${ }^{43}$ This study focused on reasons for participation, and further research is required to identify potentially modifiable barriers to participation, and to study how reasons for participation affect retention, adherence, or engagement.

\section{Acknowledgments}

We thank the HATICE participants who agreed to participate in this substudy. We also thank Suzanne van Rhijn, Alexandra Serre, and Sandra Rouquette for their help in interviewing participants; Marije Voermans, Carin Miedema, Laurie Laval, and Céline Couderc for inviting participants to complete the questionnaire; and Marieke Hoevenaar-Blom and Lennard van Wanrooij for their help with merging and analyzing data from the HATICE trial.

\section{References}

1. World Health Organization. National Institute on Aging, National Institutes of Health, Global Health and Aging; 2011.

2. Livingston G, Sommerlad A, Orgeta V, et al. Dementia prevention, intervention, and care. Lancet 2017;390:2673-2734.

3. Eurostat. Internet access and use statistics-Households and individuals. 2016. Available at: http://ec.europa.eu/eurostat/statistics-explained/index.php/Internet_ access_and_use_statistics_-_households_and_individuals. Accessed February 21, 2018.

4. Richard E, Jongstra S, Soininen $\mathrm{H}$, et al. Healthy ageing through Internet counselling in the elderly: The HATICE randomised controlled trial for the prevention of cardiovascular disease and cognitive impairment. BMJ Open 2016;6:e010806.

5. Cusack S, O'Toole PW, ELDERMET Consortium. Challenges and implications for biomedical research and intervention studies in older populations: Insights from the ELDERMET study. Gerontology 2013;59:114-121.

6. Fearn P, Avenell A, McCann S, et al. Factors influencing the participation of older people in clinical trials-Data analysis from the MAVIS trial. J Nutr Health Aging 2010;14:51-56.

7. McHenry JC, Insel KC, Einstein GO, et al. Recruitment of older adults: Success may be in the details. Gerontologist 2015;55:845-853.

8. Coley N, Andrieu S. Participation of older people in clinical trials. In: Sinclair A, Pathy J, Morley J, Vellas V, editors. Pathy's Principles and Practice of Geriatric Medicine. 5th ed. New York, NY: John Wiley \& Sons, Ltd; 2012.

9. Beishuizen CR, Stephan BC, van Gool WA, et al. Web-based interventions targeting cardiovascular risk factors in middle-aged and older people: A systematic review and meta-analysis. J Med Internet Res 2016 11;18:e55.

10. Karlin NJ, Weil J. Healthy aging in a global context: Comparing six countries. Ageing Int 2017;42:1-22.

11. Levy BR, Myers LM. Preventive health behaviors influenced by self-perceptions of aging. Prev Med 2004;39:625-629.

12. Barbera M, Mangialasche F, Jongstra S, et al. Designing an Internet-based multidomain intervention for the prevention of cardiovascular disease and cognitive impairment in older adults: The HATICE Trial. J Alzheimers Dis 2018; 62:649-663.

13. Jongstra S, Beishuizen C, Andrieu S, et al. Development and validation of an interactive Internet platform for older people: The healthy ageing through Internet counselling in the elderly study. Telemed J E Health 2017;23:96-104.

14. Andrieu S, Coley N, Gardette V, et al. Representations and practices of prevention in elderly populations: Investigating acceptance to participate in and adhesion to an intervention study for the prevention of Alzheimer's disease (ACCEPT study) - the need for a multidisciplinary approach. J Nutr Health Aging 2012;16:352-354.

15. Flick U. An Introduction to Qualitative Research. Thousand Oaks, CA: Sage Publications; 1998.

16. Plas JM, Kvale S. InterViews: An Introduction to Qualitative Research Interviewing. Thousand Oaks, CA: Sage Publications; 1996.

17. Krippendorff K. Content Analysis. An Introduction to Its Methodology. Los Angeles, CA: Sage Publications; 2004.

18. Fowler JH, Kam CD. Beyond the self: Social identity, altruism, and political participation. J Polit 2007;69:813-827.

19. Home care across Europe. Current structure and future challenges. United Kingdom: World Health Organization. 2012. Available at: http://www.euro. who.int/_data/assets/pdf_file/0008/181799/e96757.pdf.

20. Bettio F, Plantenga J. Comparing care regimes in Europe. Femin Econ 2004;10: 85-113.

21. Bolin K, Lindgren B, Lundborg P. Informal and formal care among single-living elderly in Europe. Health Econ 2008;17:393-409.

22. Reher DS. Family ties in Western Europe: Persistent contrasts. Popul Dev Rev 1998;24:203-234.

23. Drulhe M, Clément S. Inheritance of assets and taking care of elderly parents in the rural Southwest. Sociétés contemporaines 1992;10:93-109.

24. Mallon I. Support for aging in rural areas beyond intergenerational solidarity. Informations sociales; 2011:100-108.

25. Lakerveld J, Ijzelenberg W, van Tulder MW, et al. Motives for (not) participating in a lifestyle intervention trial. BMC Med Res Methodol 2008;8:17.

26. Nosraty L, Jylha M, Raittila T, Lumme-Sandt K. Perceptions by the oldest old of successful aging, Vitality 90+ Study. J Aging Stud 2015;32:50-58.

27. Molzahn AE, Kalfoss M, Schick Makaroff K, Skevington SM. Comparing the importance of different aspects of quality of life to older adults across diverse cultures. Age Ageing 2011;40:192-199.

28. Martin P, Kelly N, Kahana B, et al. Defining successful aging: A tangible or elusive concept? Gerontologist 2015;55:14-25.

29. Ligthart SA, van den Eerenbeemt KD, Pols J, et al. Perspectives of older people engaging in nurse-led cardiovascular prevention programmes: A qualitative study in primary care in the Netherlands. Br J Gen Pract 2015;65:e41-e48.

30. Reed RL, Barton CA, Isherwood LM, et al. Recruitment for a clinical trial of chronic disease self-management for older adults with multimorbidity: A successful approach within general practice. BMC Fam Pract 2013;14:125.

31. Tolmie EP, Mungall MM, Louden G, et al. Understanding why older people participate in clinical trials: The experience of the Scottish PROSPER participants. Age Ageing 2004;33:374-378.

32. European Commission. Special Eurobarometer 411. Patient safety and quality of care. 2014. Available at: https://ec.europa.eu/health/sites/health/files/ patient_safety/docs/ebs_411_sum_en.pdf.

33. Raivio R, Jaaskelainen J, Holmberg-Marttila D, Mattila KJ. Decreasing trends in patient satisfaction, accessibility and continuity of care in Finnish primary health care-A 14-year follow-up questionnaire study. BMC Fam Pract 2014; 15:98.

34. OECD, World Health Organization. State of Health in the EU. Finland. Country Health Profile 2017. 2017. Available at: http://www.oecd-ilibrary.org/docserver/ download/8117461e.pdf?expires $=1519401104 \&$ id=id\&accname=guest $\&$ checksum=FAC27E34C4EB80012E90468CB13ED730.

35. Kringos D, Boerma W, Bourgueil Y, et al. The strength of primary care in Europe: An international comparative study. Br J Gen Pract 2013 Nov;63: e742-e750.

36. Jutel A. "The expertness of his healer": Diagnosis, disclosure and the power of a profession. London: Health; 2017. 1363459317745956.

37. Townsley CA, Chan KK, Pond GR, et al. Understanding the attitudes of the elderly towards enrolment into cancer clinical trials. BMC Cancer 2006;6:34.

38. Dangour AD, Allen E, Richards $\mathrm{M}$, et al. Design considerations in long-term intervention studies for the prevention of cognitive decline or dementia. Nutr Rev 2010;68(suppl 1):S16-S21.

39. INSEE. Tableaux de l'Économie Française. 2016. Available at: https://www. insee.fr/fr/statistiques/1906701? sommaire $=1906743$. Accessed October 1, 2018.

40. StatLine. Bevolking; hoogstbehaald onderwijsniveau en onderwijsrichting. 2018. Available at: https://opendata.cbs.nl/statline/\#/CBS/nl/dataset/82816 NED/table?ts=1538388892102. Accessed October 1, 2018.

41. Statistics_Finland. Population aged 15 or over by level of education, municipality, gender and age 1970-2016. Available at: http://pxnet2.stat.fi/PXWeb/ pxweb/en/StatFin/StatFin_kou_vkour/statfin_vkour_pxt_001.px/?rxid=e8bf4 b5f-5ce7-4412-9044-54acce27dcad. Accessed September 10, 2018.

42. Agoritsas T, Deom M, Perneger TV. Study design attributes influenced patients' willingness to participate in clinical research: A randomized vignette-based study. J Clin Epidemiol 2011;64:107-115.

43. van Middelaar T, Beishuizen CRL, Guillemont J, et al. Engaging older people in an Internet platform for cardiovascular risk self-management: A qualitative study among Dutch HATICE participants. BMJ Open 2018;8: e019683. 


\section{Supplementary Material}

Table A1

Details of Recruitment Procedures for HATICE and ACCEPT-HATICE

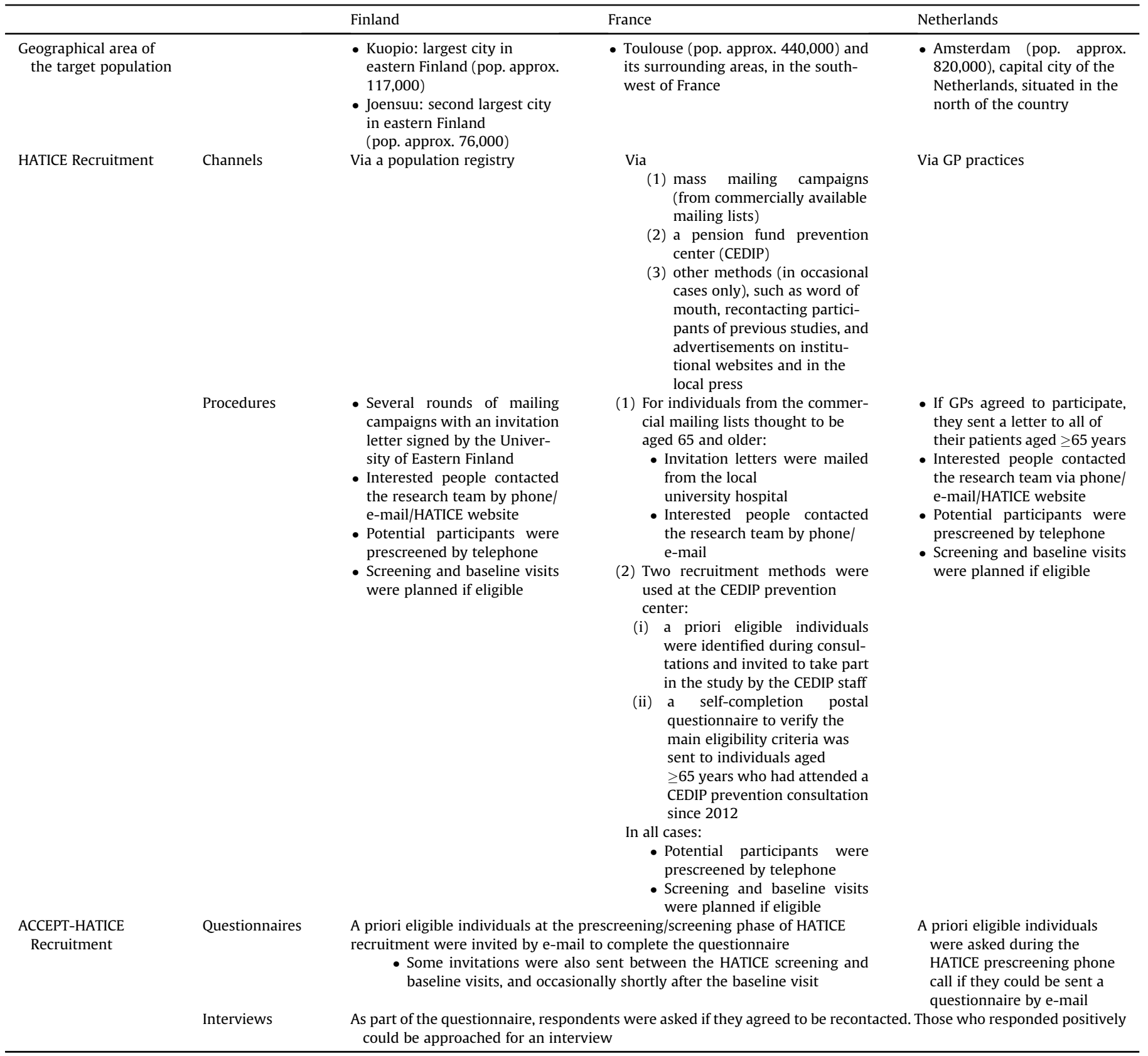


Table A2

Comparison of Baseline Characteristics of HATICE Participants Who Did and Did Not Take Part in the ACCEPT-HATICE Substudy

\begin{tabular}{|c|c|c|c|}
\hline & ACCEPT-HATICE Participants $(\mathrm{n}=343)$ & Other HATICE Participants $(\mathrm{n}=2381)$ & $P$ \\
\hline \multicolumn{4}{|l|}{ Sociodemographic characteristics } \\
\hline Age & $68.7[66.8-70.9]$ & $69.5[67.4-73.4]$ & $<.001$ \\
\hline Male & $161(47.8 \%)$ & $1263(53.0 \%)$ & .070 \\
\hline University education & $174(50.7 \%)$ & $946(39.7 \%)$ & $<.001$ \\
\hline Married/living with partner & $264(77.0 \%)$ & $1714(72.0 \%)$ & .053 \\
\hline Country & & & $<.001$ \\
\hline Finland & $191(55.7 \%)$ & $694(29.2 \%)$ & \\
\hline France & $103(30.0 \%)$ & $265(11.1 \%)$ & \\
\hline Netherlands & $49(14.3 \%)$ & $1422(59.7 \%)$ & \\
\hline \multicolumn{4}{|l|}{ Cognition, mood, and physical performance } \\
\hline MMSE & 28 [27-29] & $29[28-30]$ & $<.001$ \\
\hline GDS & $1[0-3]$ & $1[0-3]$ & .190 \\
\hline SPPB & $11[10-12]$ & $11[10-12]$ & .243 \\
\hline \multicolumn{4}{|l|}{ Cardiovascular risk profile } \\
\hline Current smoker & $20(6.2 \%)$ & $182(8.2 \%)$ & .210 \\
\hline Obesity (BMI $\geq 30)$ & $122(35.6 \%)$ & $894(37.6 \%)$ & .475 \\
\hline Hypertension & $265(77.3 \%)$ & $1979(84.7 \%)$ & $<.001$ \\
\hline Dyslipidemia & $331(96.5 \%)$ & $2294(96.7 \%)$ & .871 \\
\hline Diabetes mellitus & $60(17.5 \%)$ & $542(22.8 \%)$ & .029 \\
\hline$<150$ minutes of moderate intensity physical activity/week & $77(22.5 \%)$ & $844(35.5 \%)$ & $<.001$ \\
\hline History of CVD* & $68(20.1 \%)$ & $758(32.0 \%)$ & $<.001$ \\
\hline
\end{tabular}

Note. Bold values are statistically significant $(P<.05)$.

BMI, body mass index; CVD, cardiovascular disease; GDS, Geriatric depression scale (score/15, higher score represents more depressive symptoms); MMSE, Mini Mental Status Examination (score/30, higher score represents better cognition); SPPB, Short Physical Performance Battery (score/12, higher score represents better physical performance). Data are presented as median [IQR] or $\mathrm{n}(\%)$.

${ }^{*}$ At least 1 of the following: stroke/transient ischemic attack, myocardial infarction, angina pectoris, and/or peripheral arterial disease. 
Table A3

Quotations

Q1 What I just mentioned, I can learn things from that. And that can contribute to my health and, with the results from the complete trial, it can benefit society. That is my motive to participate. [NL-10]

Q2 Well I guess it [reason for participation] was dutifulness. When I was invited, I just thought "why not?" Since I had no reason to refuse. I didn't think about it that much. I just wondered how many visits there would be, and if I have time to attend all of them, but... There weren't a lot of visits. I didn't really think about it very much. (...) It was an automatic decision. [FI-03]

Q3 Taking care of my mother is not easy. She is 89 and she is completely dependent. (...) We can't put her in a retirement home because she doesn't want us to and so we have to take care of her ourselves. We are the last generation to do so. My daughters will not take care of me. They will not be able to; they will work until who knows when... We have already integrated the fact that for us, we will eventually end up in a retirement home. I am worried about ageing, and especially about being dependent. I see my completely dependent mother and I am projecting myself. [FR-06]

I want to help resolve the problem [of ageing] in general, and it also forces me to respect certain rules. And if it can be useful for someone else, why not? But I would say that, first and foremost, I am participating to advance medicine, just for that. (...) I don't really like the fact that I am being made to make changes, a new lifestyle, but perhaps it will also help me, bring me comfort in life and in my old age, and also be useful for others. [FR-08]

My motivation to participate is as I said before: to see if this can help me and, through me, help others. (...) I volunteer in a nursing home and I tell myself that it's not very cool to grow old like this. And I hope, through physical and mental well-being, that we can find ways to protect ourselves and stay in good health as long as possible. Because when you get into a retirement home, it's not happy. [FR-02]

Q6 Interviewer: Do you have any wishes or goals for a healthy lifestyle?

Participant: To lose weight. (...) I wish I could do liposuction. Or for someone to guide me and push me to do things [physical activity]. I give up too easily. I think it [physical activity] is boring by myself and so I would prefer to do that with someone else or an organization. [NL-09]

Q7 Well of course it [motivation for prevention] is to feel more comfortable. I feel more comfortable physically when I'm lighter, and I presume that my ailments will be milder after I lose some weight. [FI-05]

Q8 And I hope, through physical and mental well-being, that we can find ways to protect ourselves and stay in good health as long as possible. (...) I am not sure I will escape dependence, Alzheimer's disease and other pathologies. But if I can do my best to stay active as long as possible, then I should do it. [FR02]

Maybe it's the thought of not wanting to be a burden to others and that others don't need to take care of you. A strong constitution and condition and being healthy will help one feel more comfortable. (...) Some [CVD] diseases can be very mild, and they don't have much impact on daily life, but others can be quite serious. (...) That's the tricky thing: when you end up in a wheelchair or become dependent of others. With that in mind, one should aim to prevent that from happening. [FI-14]

Q10 I am really curious to see if, as a consequence of my behavioral change due to the trial, the medication I use (...) maybe my blood thinners and cholesterol medication etcetera, that we can, well maybe not stop them, but see if I can handle a lower dosage. [NL-10]

Q11 Well it made me worried [when the high blood pressure and cholesterol levels were discovered], but I was not scared. But I thought I needed to make changes now. (...) I did not really have any other options but to change my lifestyle. Or to start taking anti-hypertensives already in the mid-1990s. (...) And the diabetes drugs and so on. I rather changed my lifestyle so that I did not have to start taking those medications. [FI-04]

Q12 You pay attention that you do enough physical exercise. I know all the risk factors. I don't have high blood pressure or those kind of things. But I don't eat a lot of salt. So I incorporate it in my life. And I think it would be an insult to those who have treated me if I didn't do that. A piece of gratitude also. And I think that is a sort of obligation that I feel. [NL-01]

Q13 Yes, I had hoped that they [from the HATICE trial] would conclude that I was very healthy ( ...), that there is nothing wrong with my arteries and heart. [NL07]

Q14 Well, [I decided to participate] just because I'm so lazy to book an appointment or see the doctor. I've already been in so many trials, I've always received the medical check-up there. Like for example my thyroid disease that was discovered in one of these studies, I probably wouldn't have seen a doctor otherwise. It is good to have regular follow-up and monitoring if something occurs. And it's free of charge. And all the appointments are booked for me and I don't need to... It is good that it's so easy (...) I'm too lazy to book any appointments. In this trial they do all the blood tests regularly and I know exactly where I stand. [FI-13]

Q15 After retirement, there are no regular follow-ups anymore. One should seek medical attention himself, if needed. (...) And maybe [I decided to participate] also because I'm not in working life anymore. One doesn't go to the health care center every year or even every other year to get the blood tests and other things done. Somehow it feels that they [health care professionals] are so busy and it's impossible to reach them. Therefore, it just doesn't get done. I just mentioned earlier to you that the health care system works well, but actually, when you need the services, it's difficult to access. And then the fact that I'm not sick and I should explain them why I need the blood tests and why my values need to be monitored. I don't know if I've got the right impression, but sometimes it feels like they don't think it's necessary at all. A healthy person just wants to get tested for no reason. When I found out about this trial, I thought that, at least for 18 months, someone will examine me. [FI-07]

Q16 My father has both heart disease and a memory disorder. Of course, I'm interested in finding out what my situation is. [FI-09]

Q17 I said yes [to the study] because, with Internet, it is not constraining. I can access the website anytime, even at night. [FR-09]

Q18 Well, in this kind of a study, I think that... The premise is that it (the information) is reliable. (...) I have learned that information and knowledge generated at the university is reliable (...). (Interviewer: Right. So you trust the information you read in this study?) Yes. (Interviewer: What about information you read online?) Yes, well that should be viewed critically. [FI-05]

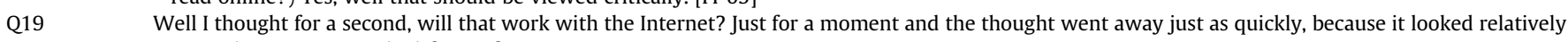
easy. That was not too bad. [NL-07]

Q20

(Interviewer: What was the reason you agreed to participate to HATICE, when you previously declined to participate in other studies?) I think it was because of the way I was approached. It was just very clear and it was via my GP. Then I think, well that is probably very serious. That is not... someone can't do anything crazy with that or whatever. Reliable, that is what I mean. [NL-07]

Yes, they asked us and we felt honored. I was very proud of it. Because I said to my son and brother-in-law, well we are participating in a study from the AMC [University Medical Centre]. He says, do you have to go there every time? I said, no, they come to my GP, so it is very close. [NL-04]

Each quotation is accompanied by the country and number of the participant in brackets. $Q$ indicates the quotation number. 


\begin{tabular}{|c|c|c|c|c|c|c|}
\hline & \multicolumn{4}{|c|}{ I agree with this statement: } & \multicolumn{2}{|c|}{$\begin{array}{l}\text { This is a reason why I accepted to } \\
\text { participate in the HATICE study: }\end{array}$} \\
\hline & $\begin{array}{l}\text { Totally } \\
\text { agree }\end{array}$ & $\begin{array}{l}\text { Somewhat } \\
\text { agree }\end{array}$ & $\begin{array}{l}\text { Somewhat } \\
\text { Disagree }\end{array}$ & $\begin{array}{l}\text { Totally } \\
\text { Disagree }\end{array}$ & Yes & No \\
\hline 1. I am interested in contributing to scientific progress & $\square$ & $\square$ & $\square$ & $\square$ & $\square$ & $\square$ \\
\hline $\begin{array}{l}\text { 2. My family and friends encouraged me to } \\
\text { participate in the HATICE study }\end{array}$ & $\square$ & $\square$ & $\square$ & $\square$ & $\square$ & $\square$ \\
\hline $\begin{array}{l}\text { 3. Participating in the HATICE study will } \\
\text { help me to occupy my free time }\end{array}$ & $\square$ & $\square$ & $\square$ & $\square$ & $\square$ & $\square$ \\
\hline $\begin{array}{l}\text { 4. Participating in the HATICE study } \\
\text { will help me to improve my diet }\end{array}$ & $\square$ & $\square$ & $\square$ & $\square$ & $\square$ & $\square$ \\
\hline $\begin{array}{l}\text { 5. Participating in the HATICE study will help me } \\
\text { to increase my level of physical exercise }\end{array}$ & $\square$ & $\square$ & $\square$ & $\square$ & $\square$ & $\square$ \\
\hline $\begin{array}{l}\text { 6. Participating in the HATICE study will enable me } \\
\text { to receive specific medical monitoring }\end{array}$ & $\square$ & $\square$ & $\square$ & $\square$ & $\square$ & $\square$ \\
\hline $\begin{array}{l}\text { 7. Improving my diet and/or increasing my level of } \\
\text { physical exercise can have benefits on my health }\end{array}$ & $\square$ & $\square$ & $\square$ & $\square$ & $\square$ & $\square$ \\
\hline 8. I am worried about my health & $\square$ & $\square$ & $\square$ & $\square$ & $\square$ & $\square$ \\
\hline $\begin{array}{l}\text { 9. An internet-based program is an effective way } \\
\text { to improve my health }\end{array}$ & $\square$ & $\square$ & $\square$ & $\square$ & $\square$ & $\square$ \\
\hline $\begin{array}{l}\text { 10. An internet-based program is a fun way } \\
\text { to improve my health }\end{array}$ & $\square$ & $\square$ & $\square$ & $\square$ & $\square$ & $\square$ \\
\hline 11. I like using the internet & $\square$ & $\square$ & $\square$ & $\square$ & $\square$ & $\square$ \\
\hline $\begin{array}{l}\text { 12. Participating in the HATICE study will help me } \\
\text { to improve my internet skills }\end{array}$ & $\square$ & $\square$ & $\square$ & $\square$ & $\square$ & $\square$ \\
\hline $\begin{array}{l}\text { 13. Thanks to the internet, I can follow the program } \\
\text { when and where I want }\end{array}$ & $\square$ & $\square$ & $\square$ & $\square$ & $\square$ & $\square$ \\
\hline $\begin{array}{l}\text { 14. Participating in an internet-based program is a way } \\
\text { to show myself that I am modern (up-to-date) }\end{array}$ & $\square$ & $\square$ & $\square$ & $\square$ & $\square$ & $\square$ \\
\hline 15. Please specify any other reasons you have for participating: & $\square$ & $\square$ & $\square$ & $\square$ & $\square$ & $\square$ \\
\hline 16. & $\square$ & $\square$ & $\square$ & $\square$ & $\square$ & $\square$ \\
\hline
\end{tabular}

Of all of these reasons, which is the main reason why you accepted to participate in the HATICE study? Please write in the box below the number (from the table above) corresponding to this reason:

The main reason why I accepted to participate in the HATICE study is the reason $n^{\circ}{ }_{-}|\ldots|$

Would you agree to be re-contacted by a researcher to answer some further questions?

$\square$ YES $\square$ NO.

ACCEPT-HATICE interview guide

[Examples of potential questions are given in italics]

\section{Reconstruction of life-course}

Introduction: First of all, I would like you to introduce yourself and to tell me about your daily activities.

Sociodemographic data

- Marital status, number of children \& grandchildren, family and friends, geographical proximity, retirement

Environmental and psychosocial factors related to health and quality of life

- Perceived and actual social support

- Social and cultural activities (leisure activities); Daily activities (domestic activities)

- Type of personality

Can you tell me a bit more about your family and friends? Can you tell me a bit more how you spend your time?

\section{Relationship with health and perceived health status}

Introduction: I would like you to tell me about your health practices and how you react when you are faced with medical problems.

Health practices: evaluation of the interviewees' behavior when they have a health problem
- Relationship with doctors or medical/health professionals, frequency of consultations

- Relationship with medications (e.g. preference for prescribed or over the counter medications, or complementary medicine)

When you have a medical problem or a question about your health, what steps do you take? (E.g. in terms of consulting a doctor, or taking medication).

Perceived and actual health status

- Coping strategies for health problems In general, how do you cope with health problems (for example, illness)? Do you tend to look for a solution? To ask for help or advice? Or do you generally tend to rely only on yourself? Do you tend to focus on a problem, or avoid it? Try to forget it?

- Causal attribution (origin and responsibility of illness) and locus of control

What do health and illness mean to you? What do you think about your health? Does it depend on you? On your doctors? On chance or destiny? Would you say that being ill is a punishment?

\section{Perception of cardiovascular disease (CVD) risk and} prevention

Introduction: I would like you to tell me about cardiovascular disease: what it means to you and whether/how it can be prevented.

Exploration of beliefs about CVD (e.g. origin/cause, quest of meaning).

Level of knowledge about risks, management, and consequences associated with CVD and risk factors.

What do you know about cardiovascular disease and its management? What does it mean to you? What can one do to manage this disease or prevent it worsening? 
Prevention practices for CVD and risk factors

What is your personal situation in terms of cardiovascular disease? Could you tell me what do you do to try to manage or prevent cardiovascular disease? And how do you find out what you should do? Do you look for information about health in general and about specific health problems that you may encounter?

Perceived utility and effectiveness of prevention of CVD via dietary habits, physical activity, medication.

Role of Internet and online support in promoting healthy aging and preventing CVD
- Advantages and disadvantages of using Internet for health and prevention

- Level of credibility of information on the Internet

- Perceived effectiveness of prevention of CVD and potential risks

Could you tell me about how you use the internet (frequency, uses, on their own or with help, etc.)? What do you think about prevention on the internet? In what way do you think that internet can be a useful tool for your health?

\section{Reasons for participation in the HATICE trial}

Introduction: Could you tell me about where you are up to in the HATICE trial, and why you decided to participate? 